\title{
RECONCEITUANDO LINGUAGEM E DISCURSO NO REFERENCIAL DE WENGER SOBRE COMUNIDADES DE PRÁTICAS
}

\author{
Reconceptualizing language and discourse within Wenger's Communities \\ of Practice framework
}

\author{
Regina Celia HALU \\ Universidade Federal do Paraná \\ reginah@ufpr.br \\ https://orcid.org/0000-0002-8251-1650
}

\begin{abstract}
RESUMO: Este artigo apresenta uma proposta de reconceitualização de linguagem e discurso no referencial de comunidades de prática (CP) de Lave e Wenger (LAVE; WENGER, 1991; WENGER, 1998). Wenger adota o conceito de discurso de Gee (1992), mas sem compreender discurso como prática social. Com relação à negociação de significados dentro de práticas sociais, a explicação se baseia nos processos de participação e reificação. Linguagem aparece em alguns dos exemplos de produtos derivados de tais processos, recebendo um tratamento limitado e, por vezes, incongruente. Objetivando adaptar o referencial de Wenger para a área de Linguística Aplicada e formação de professores, na presente proposta linguagem é conceitualizada como discurso, conforme discutido por Foucault (2000), apoiando-se também nas reflexões de Maturana $(2001,2005)$ sobre linguagem. Tal adaptação torna o referencial de CP mais específico para pesquisas na área de línguas e formação de professores, que explorem práticas discursivas. PALAVRAS-CHAVE: Linguagem; Discurso; Comunidades de Prática.
\end{abstract}

ABSTRACT: This article presents a proposal of reconceptualization of language and discourse in Lave and Wenger's communities of practice (CP) framework (LAVE; WENGER, 1991; WENGER, 1998). Wenger adopts Gee's concept of discourse (1992), but without taking discourse as social practice. In relation to the negotiation of meaning within social practices, the explanation is based on the processes of participation and reification. Language appears in some of the examples of products that would derive from them, receiving a limited and sometimes incongruous treatment. Aiming at adapting Wenger's framework for the area of language studies and teacher education, in the present proposal language is conceptualized as discourse, as

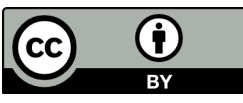


discussed by Foucault (2000), and supported as well by Maturana's reflections on language $(2001,2005)$. Such adaptation makes the CP framework more specific for research in the area of Applied Linguistics and teacher education, exploring discursive practices. KEY-WORDS: Language; Discourse; Communities of Practice.

\section{INTRODUÇÃO}

Considerando que o conceito de comunidade de prática $(\mathrm{CP})$, inserido em um referencial baseado em uma concepção social de aprendizagem, tem sido produtivamente utilizado no Brasil para o desenvolvimento de pesquisas na área de ensino e aprendizagem de línguas e formação de professores de línguas (CALVO, 2017; CALVO; FREITAS, 2014; FOGAÇA; HALU, 2017; MACHADO; GIL, 2017; SILVA, 2013; TANACA; MATEUS, 2014), proponho aqui oferecer uma reformulação do conceito de linguagem dentro, especificamente, da proposta desenvolvida inicialmente por Lave e Wenger (1991) e expandida por Wenger (1998), o que pode ser útil como ferramenta teórica para pesquisas nessas áreas da Linguística Aplicada ${ }^{1}$. Justamente por tomar o referencial de comunidades de prática como procedimento analítico, refiro-me apenas a essas duas publicações. Em publicações posteriores, a proposta tende a ser apresentada como um modelo de trabalho colaborativo, voltado para gestão de conhecimento, para implementação em organizações e empresas diversas (WENGER et al., 2002).

A crítica que construo parte da observação de que na apresentação de sua visão de aprendizagem como prática social em comunidades, Wenger (1998) acabou por não enfocar o uso e construção da língua, assim como o fenômeno maior da linguagem, no qual ela se insere, como prática social, mas usar o conceito de reificação (em geral, em conexão com a modalidade escrita da língua, tomando textos como produtos) e o de participação (para instâncias de oralidade). Isso acabou criando dúvidas e deixando hiatos justamente quanto aos conceitos de língua, linguagem e discurso e suas relações com a noção de aprendizagem como prática social, em especial quando se busca estudar comunidades formadas em torno das práticas de aprender e ensinar línguas.

\footnotetext{
${ }^{1}$ A proposta que apresento aqui foi utilizada inicialmente em minha pesquisa de doutorado (HALU, 2010) e aprofundada para minha pesquisa no estágio de pós-doutorado, realizado entre 2017 e 2018, na Universidade Federal de Santa Catarina, sob supervisão da Prof ${ }^{\mathrm{a}}$. Dra ${ }^{\mathrm{a}}$. Gloria Gil. A pesquisa do doutorado enfocou as práticas formativas de uma comunidade de prática composta por professoras universitárias de língua inglesa trabalhando em um programa de extensão universitária. No pós-doutorado, pesquisei as atitudes pedagógicas de parte de duas comunidades de professores universitários de Letras frente às recentes mudanças no status da língua inglesa no mundo.
} 
Inicio apresentando, brevemente, a conceituação de comunidades de prática, tratando, em seguida, das explicações dadas em Wenger (1998) para a negociação de significados nas práticas sociais, por meio dos conceitos de reificação e participação. Nessas explicações se incluem a tentativa de utilizar o conceito de discurso expresso por Gee (1992) e a desconsideração de discursos como práticas nelas mesmas. Passo então à crítica a partir dos exemplos de linguagem verbal que são dados para os processos de reificação e participação. Ao fim, apresento uma proposta de reconsideração dos conceitos de discurso e linguagem (aí incluídas as línguas) como práticas sociais, com base em Maturana (2001, 2005) e Foucault (2000).

\section{COMUNIDADES DE PRÁTICA}

Uma comunidade de prática é uma configuração social em que os participantes estão envolvidos em práticas colaborativas, negociando objetivos comuns e na qual a aprendizagem é um aspecto intrínseco. Cada comunidade tem seu próprio tempo de emergência, desenvolvimento e dispersão, com a construção de seus próprios discursos, rotinas e artefatos. Para Wenger (1998, p.6), as comunidades estão em todo lugar, mas ele considera que esse conceito não pode ser aplicado a toda configuração social. Tal conceito serviria melhor para lidar com configurações de nível intermediário, não se aplicando a uma atividade ou interação específica (como uma conversação), nem a configurações amplas como instituições (como escolas, empresas) e sistemas (como nações e culturas). Se aplicado às específicas, não seria possível observar continuidades no tempo e entre as pessoas com relação aos empreendimentos e identidades dos quais são parte; quanto a tratar de configurações maiores, seriam as descontinuidades entre diversos espaços menores, com seus conjuntos de práticas, que seriam perdidas de vista (WENGER, 1998, p. 125). Por essa razão, o conceito de comunidades de prática tem se mostrado adequado para o estudo de comunidades tais como grupos de professores e/ou alunos e/ou pesquisadores envolvidos em práticas de aprendizagem e ensino de línguas, de pesquisa sobre tais práticas, sobre participação e trajetórias desses participantes na definição e busca de seus objetivos educacionais por meio de seu repertório de práticas sociais. Um exemplo recente de pesquisa é o trabalho desenvolvido por Ferreira (2019), o qual utilizou o conceito de comunidades de prática para auxiliar na discussão de questões de identidade e investimento, negociadas entre alunos ouvintes de um curso de Letras Libras. Walesko (2019), em sua tese, também usou o conceito em seu referencial teórico para discutir o papel do mito do falante nativo na formação inicial de professores de inglês, delimitando sua investigação às interações discursivas da comunidade de prática 
"Inglês-IsF/UFPR", formada por alunos-professores de Letras e assistentes de ensino de inglês ("English Teaching Assistants - ETA") do programa ETAs CAPES-Fulbright², ao longo de 2 anos.

Em geral, pesquisas usando o referencial teórico das CPs para estudos na área das linguagens (na Educação e na Linguística Aplicada) enfocam o comportamento de comunidades de aprendizes, professores e formadores, procurando interpretar os movimentos de seus membros, e não se concentram nas práticas discursivas construídas nas mesmas, embora possam se basear na interpretação de suas produções discursivas. Também não buscam explicitar o conceito de língua ou de linguagem dentro do referencial das CPs ou a relação entre práticas sociais e práticas discursivas. Um exemplo desse tipo de uso pode ser visto na pesquisa de doutorado desenvolvida por Ramos (2011), a qual, tratando dos Grupos de Trabalho em Rede (GTR) do Programa de Desenvolvimento Educacional (PDE) do Paraná, realiza uma interpretação das manifestações escritas das professoras participantes nos fóruns online promovidos. Não há uma conceituação explícita de língua, linguagem ou discurso como base para o trabalho interpretativo dos dados gerados, embora o termo discurso apareça vinculado a campos como o governamental e o acadêmico e ainda seja citado como conteúdo estruturante para o ensino de segunda língua segundo as Diretrizes Curriculares Estaduais (PARANÁ, 2008).

Ramos toma três conceitos propostos por Wenger (1998) como básicos para sua pesquisa: aprendizagem, participação e reificação (p. 80). Seu texto resume bem os conceitos: aprendizagem "não é uma atividade separada do cotidiano", ela faz "parte de nossa participação em nossas comunidades e organizações nas quais atuamos" e participação é o "processo de se tornar participantes ativos nas práticas das comunidades sociais, construindo identidades na relação com essas comunidades", é "a experiência social de viver em um mundo, considerando o pertencimento em comunidades sociais e o ativo envolvimento em trajetórias sociais" (RAMOS, 2011, p.80). Quanto ao termo reificação, ele é entendido como "o ato de tratar algo que é essencialmente abstrato como algo concreto":

[...] Em outras palavras, a reificação é o processo de dar forma à nossa experiência, produzindo objetos que solidificam esta experiência como algo concreto. Qualquer comunidade de prática produz abstrações, ferramentas, símbolos, histórias, termos e conceitos que reificam algo daquela prática de forma sólida (WENGER, 1998, p.59). (RAMOS, 2011, p. 81)

\footnotetext{
${ }^{2}$ Para informações sobre o Programa ETAs, acesse: http://fulbright.org.br/edital/institucionaletas.
}

Revista X, v. 16, n. 6, p. 1600-1613, 2021. 
É essa compreensão de reificação juntamente com o tratamento dado aos conceitos de discurso, linguagem e práticas sociais no referencial de CP proposto por Wenger que discuto a seguir.

\section{NEGOCIAÇÃO DE SIGNIFICADOS NAS PRÁTICAS SOCIAIS}

Segundo Wenger, falar em práticas sociais é "falar sobre recursos sociais e históricos, quadros referenciais e perspectivas compartilhados que podem sustentar mútuo engajamento na ação" (1998, p. 5). Essa ação não se refere somente à ideia de fazer alguma coisa, mas de fazê-las em um contexto sócio-histórico que dá estrutura e significado ao que se faz. O conceito é amplo:

Tal conceito de prática inclui tanto o explícito como o implícito. Ele inclui o que é dito e o que se deixa de dizer; o que é representado e o que é presumido. Ele inclui a língua, ferramentas, documentos, imagens símbolos, papéis bem definidos, critérios especificados, procedimentos codificados, regulamentações e contratos que várias práticas deixam explícitas por uma série de razões. Mas também inclui as relações implícitas, convenções tácitas, dicas sutis, regras práticas não ditas, intuições reconhecíveis, percepções específicas, sensibilidades bem sintonizadas, entendimentos incorporados, pressupostos subjacentes e visões de mundo compartilhadas. A maior parte disso pode nunca ser articulada, contudo são sinais evidentes de participação em sociedades de prática e são cruciais para o sucesso de seus empreendimentos. (WENGER, 1998, p. 47, minha tradução) ${ }^{3}$

Apesar de, segundo a explicação e exemplos acima, aparentemente, tudo ser prática, e de Wenger (1998, p. 51) considerar que é na prática que são gerados os significados, ele não trata da negociação desses significados como ocorrendo discursivamente. Embora afirme apoiar-se em Foucault quando utiliza o termo discurso em seu trabalho, ele se afasta da noção de discursos como práticas que constroem a realidade (FOUCAULT, 2000, p. 55).

\footnotetext{
${ }^{3}$ Texto original: Such a concept of practice includes both the explicit and the tacit. It includes what is said and what is left unsaid; what is represented and what is assumed. It includes the language, tools, documents, images, symbols, well-defined roles, specified criteria, codified procedures, regulations, and contracts that various practices make explicit for a variety of purposes. But it also includes all the implicit relations, tacit conventions, subtle cues, untold rules of thumb, recognizable intuitions, specific perceptions, well-tuned sensitivities, embodied understandings, underlying assumptions, and shared worldviews. Most of these may never be articulated, yet they are unmistakable signs of membership in communities of practice and are crucial to the success of their enterprises.
} 
Prefere referir-se a James Gee ${ }^{4}$, tomando discurso como "um recurso interativo, social para construir declarações sobre o mundo e coordenar o engajamento na prática" (WENGER, 1998, p. 289). De fato, o conceito de comunidades de prática se relaciona bem com a noção de discurso como "uma associação socialmente aceita entre maneiras de usar a linguagem, de pensar e de agir que podem ser usadas para identificar alguém como um membro de um grupo ou 'rede social' socialmente significativo" (GEE, 1989, p. 18).

Wenger (1989, p. 289), enfim, escolhe não aprofundar o entendimento de discurso como prática social, apenas dizendo que não considera os discursos como 'práticas nelas mesmas" (1998, p. 129) e que usará os conceitos de participação e reificação para discutir a negociação de significados. Participação refere-se a um processo de engajamento nas relações sociais em comunidades. Nesse processo, existe a possibilidade do que Wenger chama de "reconhecimento mútuo", ou seja, o reconhecimento do outro e de si mesmo à medida que se negociam significados nas relações estabelecidas em torno dos empreendimentos de uma comunidade. É o conceito que utiliza para refletir sobre a construção identitária, que ocorreria através dessas relações de participação (WENGER, 1998, p. 56). Quanto à reificação, ele considera que no processo de negociação de significados, os participantes "projetam [seus] significados no mundo e então os percebem como existindo no mundo, tendo uma realidade própria" (p. 58). Esse processo de objetificação seria necessário e central para toda prática, com sua produção de símbolos, histórias, termos e conceitos.

Wenger explica que enxerga a linguagem como traduzindo a realidade e não pressupõe "uma correspondência inerente entre um símbolo e um referente, uma ferramenta e uma função ou um fenômeno e uma interpretação" (1998, p. 60-61). Ele vai tratar de questões relacionadas a representação e realidade com o conceito de reificação. Ele explica que a noção de dar um status de objeto a algo que realmente não é um objeto pode criar uma "ilusão útil" de solidez ou estabilidade das formas reificadas, que facilita a negociação de significados, mas que a reificação não leva à criação de um objeto que pode ser destacado do contexto em que foi produzido. Explica que a forma reificada é como "a ponta de um iceberg, que indica contextos maiores de significação realizada em práticas humanas" (WENGER, 1998, p. 61). A reificação seria mais bem caracterizada como um processo contínuo e incompleto, "potencialmente enriquecedor e potencialmente enganador" (p. 62). O perigo ilusório de uma reificação estaria, por exemplo, em acreditar que ao nomear um processo, ao produzir uma interpretação de uma

\footnotetext{
${ }^{4}$ GEE, James Paul. The Social Mind: language, ideology, and social practice. New York: Bergin and Garvin, 1992.
}

Revista X, v. 16, n. 6, p. 1600-1613, 2021. 
prática, os participantes de uma comunidade compreenderiam completamente o processo ou a prática, dariam conta do significado do processo ou da prática, que se manteria fixo e concentrado (p. 61).

\section{CONSIDERAÇÕES CRÍTICAS}

Inicio minha crítica quanto à argumentação desenvolvida por Wenger com base nos conceitos de participação e reificação analisando os exemplos escolhidos e na linguagem usada por ele para tratar da construção de significados nas práticas sociais (cf. HALU, 2010). Como exemplos de participação na negociação de significado, ele se refere a embaixadores que se encontram com autoridades para negociar os tratados apresentados, juízes que se reúnem para interpretar leis, serviços de assistência aos usuários de produtos. Esses exemplos tendem a conectar participação a interações verbais orais. Como exemplos de reificação encontram-se monumentos, anotações, atas, tabelas de horários, programa de computador, poemas. A reificação se liga a formas de linguagem (e o que poderia ser tratado como 'produtos culturais') com uma característica de 'materialidade' (que pode ser a palavra escrita ou um monumento de pedra). Além do uso de termos como "ilusório" e "enganador" para tratar do potencial gerativo de significados de uma "reificação", Wenger (1998, p. 62) ainda se refere às próprias palavras como um exemplo de reificação por serem "projeções de significado humano" e à maneira como elas funcionariam como "atalhos para a comunicação".

É certo que, ao falar da aparente solidez das reificações e da praticidade de tomálas ilusoriamente como fixas e independentes, Wenger se aproxima do entendimento de que é impossível alcançar a definição final de um signo, uma vez que seu significado é construído em função das relações, sempre em mudança, que se estabelecem com outros signos dependendo de seu contexto sócio-histórico de uso. Entretanto, considerando os exemplos dados, ele parece ficar mais próximo de uma racionalidade cartesiana, limitada a uma materialidade física palpável ou visível, na qual a língua funcionaria como um recurso que permitiria ao ser humano aproximar-se continuamente de uma realidade última. Analisando seus exemplos, também é possível equacionar, com relação mais especificamente à linguagem verbal, participação com a língua falada, tomada como instável e evanescente, e reificação com a língua escrita, vista como estável e material. Além disso, se as palavras são "atalhos" para a comunicação, interações verbais poderiam ser vistas como formas de comunicação em que negociar significados não significaria construir entendimentos no embate de interesses, mas somente encapsular significados em formas momentaneamente estáveis para uma operação de troca (a língua como canal 
para mensagens). Não é isso que ele afirma propor, mas é para isso que seus exemplos apontam.

Concluo, como ponderei anteriormente (HALU, 2010, p. 51-52), que, dessa forma, gera-se dúvida quanto a

[...] quais pressupostos são tomados em relação ao que Wenger entende por realidade e linguagem. Parece, por vezes, que a linguagem não é reconhecida como constituinte da realidade - como se existisse à parte. Ao mesmo tempo, ela é apresentada como uma ferramenta para "objetificar" conceitos e abstrações. [...] No meu entendimento, como Wenger não considera a realidade discursiva, ele acaba por ter de manter uma compreensão da linguagem como produtora de reflexos das práticas, como representação da realidade, o que considero limitante para a noção de significados sendo produzidos nas práticas sociais que é central para seu trabalho.

\section{LINGUAGEM COMO DISCURSO, DISCURSO COMO PRÁTICA SOCIAL}

Daí a necessidade de olhar com atenção para o papel da linguagem quanto a essa produção e negociação de significados. Minha opção foi repensar a discussão de Wenger sobre reificação considerando como Maturana (2001) considera o ato de distinção que nós como seres vivos operamos. Para Maturana a cognição se dá no espaço das interações sociais, e ele a toma como inseparável do nosso viver na linguagem:

[...] somos observadores no observar, no suceder do viver cotidiano na linguagem, na experiência na linguagem. Experiências que não estão na linguagem, não são. Não há modo de fazer referência a elas, nem sequer fazer referência ao fato de tê-las tido. "Escuta, sabe, me aconteceu algo que não posso descrever." Esse "não posso descrever" já pertence à linguagem. (MATURANA, 2001, p. 28)

Para nós que observamos na linguagem, distinguir é o ato cognitivo básico, e, "embora nada preceda o ato de distinção, uma vez que entidades são distinguidas, nós observadores podemos e de fato passamos a tratá-las como independentes" (GRACIANO, 1997, p. 142). Passamos a tratá-las como os pontos de foco a que se refere Wenger (1998, p. 58), em torno dos quais é possível continuar a organização da negociação de significados. Wenger (1998, p. 228) diz, por exemplo, que as comunidades existem desde sempre. Só é possível dizer que elas existem "desde sempre" dentro do quadro de significados construídos em torno da própria noção de CP. Elas existem desde o momento 
(o "sempre") quando Lave e Wenger construíram e compartilharam essa distinção para uma configuração social, imersos no observar de diferentes práticas e negociando o significado de aprender; isto é, desde que fizeram essa distinção e a compartilharam com pesquisadores, empresários, professores, passando todos a participar de sua contínua explicação, imersos num fluxo discursivo.

Dentro dessa explicação é que é possível falar sobre a emergência de comunidades como parte da realidade das práticas. As CPs têm sido vistas como uma configuração social que se desenvolve à medida que práticas situadas se interconectam ao longo do tempo e pelas quais e nas quais os indivíduos dão significado às suas participações. Se eu, como pesquisadora, utilizar o conceito de comunidades de prática como ferramenta interpretativa, será na prática de minha pesquisa que vou contribuir para fazer 'emergir' ou fazer 'iniciar' uma comunidade, uma comunidade que seria movida pelo engajamento em torno da negociação e realização de objetivos comuns. Os próprios membros dessa comunidade e aqueles com quem se relacionam podem vir a participar dessa construção de um discurso sobre aprendizagem, linguagem e práticas sociais, sob o termo "comunidade de prática". É apenas dessa maneira que concordo com Wenger (1998, p. 49) ao considerar que comunidades de prática não passam a existir por decreto. Um indivíduo ou uma instituição não tem como criar uma comunidade de prática apenas nomeando uma dada configuração; sua emergência é dependente das práticas discursivas que irão construir sua identidade como tal, mas o "batismo" que nomeará um grupo como uma CP, seja por um pesquisador ou por membros do grupo, é uma dessas práticas.

Se Wenger (1998, p. 129) deixa explícito que não toma os discursos como "práticas nelas mesmas", Foucault (2000, p. 55) coloca que os discursos devem ser tratados "como práticas que formam sistematicamente os objetos de que falam" e explica que "as coisas não têm o mesmo modo de existência, o mesmo sistema de relações com o que as cerca, os mesmos esquemas de uso, as mesmas possibilidades de transformação depois de terem sido ditas" (2000, p. 143). Assim como Maturana (2005, p. 38) nos vê como estando na linguagem, isto é, vivendo na linguagem, Foucault (2000, p. 20-21) diz que somos "seres de linguagem e não seres que possuem linguagem". Proponho, assim, reformular parte do embasamento da proposta de comunidades de prática, considerando que a negociação e construção de significados acontecem em práticas discursivas e não-discursivas e de forma mutuamente implicada. Segundo Foucault, as práticas discursivas não devem ser confundidas com

[...] a operação expressiva pela qual um indivíduo formula uma ideia, um desejo, uma imagem; nem com a atividade racional que pode ser 
acionada num sistema de inferência; nem com a "competência" de um sujeito falante quando constrói frases gramaticais; é um conjunto de regras anônimas, históricas, sempre determinadas no tempo e no espaço, que definiram, numa dada época, e para uma determinada área social, econômica, geográfica ou linguística, as condições de exercício da função enunciativa. (FOUCAULT, 2000, p. 136)

Assim, ao lidar com práticas discursivas na discussão do aprendizado em $\mathrm{CP}$, não considero discurso exatamente nos termos propostos por Wenger, meramente como recurso para construção de declarações sobre o mundo. Considero a afirmação de Foucault (2000, p. 55) de que os discursos fazem mais do que usar os signos de que são feitos para designar coisas; o discurso como prática permite pensar na linguagem (e, como parte dela, na língua) como algo além da concepção de sistemas abstratos de signos existindo independentemente de seu contexto de uso. Permite fazer a escolha que teria sido descartada por Saussure (2006, p. 17) e se aproximar da linguagem que ele mesmo descreveu como "multiforme e heteróclita; a cavaleiro de diferentes domínios, ao mesmo tempo física, fisiológica e psíquica" e que "pertence além disso ao domínio individual e social".

Em uma comunidade de prática, os participantes encontram-se formando e sendo formados por práticas discursivas e não-discursivas. A visão de prática como fonte de coerência de uma comunidade deve-se aos efeitos de seus conjuntos de regras anônimas e históricas em que se estabelece a possibilidade de engajamento mútuo, de negociação de um empreendimento conjunto e da construção de um repertório de recursos - rotinas, ferramentas, conceitos, gestos e histórias, caracterizando as comunidades como entidades sociais dinâmicas (WENGER, 1998, 72-85).

\section{CONSIDERAÇÕES FINAIS}

Com essa reformulação das relações entre língua, discursos e práticas, deve ser possível examinar melhor o funcionamento de comunidades caracterizadas por intenso questionamento dos pressupostos de suas práticas, tal como tendem a ser comunidades de professores, professores e alunos, formadores e professores de línguas com relação às suas práticas de educação, formação, pesquisa, ensino e aprendizagem. Nelas, conflitos emergem de forma produtiva a partir do engajamento em interações que possibilitam o uso de diferentes estratégias lógico-argumentativas, em debates reflexivos que questionam diversas formas de conhecimento e abordagens para o ensino e aprendizagem, em práticas 
de aprendizagem colaborativa em que diferentes discursos sobre educação, conhecimento e língua se cruzam (JORDÃO, 2009, p. 103).

As considerações que apresentei surgiram da necessidade de desenvolver um arcabouço teórico adequado tanto para pesquisas na área de línguas e formação de professores, como para minha própria prática docente na universidade. Ao longo dos últimos anos, minha práxis continuou a se desenvolver com base nesse esforço de alinhar as ferramentas oferecidas pela proposta de comunidades de prática (WENGER, 1998; LAVE; WENGER, 1998) às propostas de questionamento conceitual, conforme vinham sendo concebidas por Jordão (2007a, 2007b, 2009), Andreotti (2008, 2011) e pelas professoras pesquisadoras atuantes no Núcleo de Assessoria Pedagógica - NAP ${ }^{5}$ (DELEM-UFPR) a partir dos pressupostos do letramento crítico (JORDÃO et al., 2011). Vejo que isso tem permitido a mim e a meus colegas de pesquisa tratar de questões chaves para a atuação de professores e formadores na área de LE, tal como as concepções de língua e conhecimento e suas relações com o ensino de LE e a educação. Espero que compartilhar essa discussão em torno de língua, linguagem, discurso e comunidades de prática possa ser útil para processos que envolvam principalmente o exercício de uma agência discursiva e a criação de espaços abertos para questionamentos na formação de professores de línguas.

\section{REFERÊNCIAS}

ANDREOTTI, Vanessa. Innovative methodologies in global citizenship education: the OSDE initiative. In: GIMENEZ, Telma; SHEEHAN, Susan. Global citizenship in the English language classroom. London: British Council, 2008. p. 40-47.

ANDREOTTI, Vanessa. Relativizing Western knowledge production in spaces of dissensus: the OSDE methodology. In: ANDREOTTI, Vanessa. Actionable Postcolonial Theory in Education. Postcolonial Studies in Education. New York: Palgrave Macmillan, 2011.

\footnotetext{
${ }^{5}$ O Núcleo de Assessoria Pedagógica (NAP), ligado ao Departamento de Letras Estrangeiras Modernas (DELEM) da UFPR, desenvolve atividades de extensão voltadas para a formação continuada de professores de línguas, principalmente do ensino público regular. Mais informações estão disponíveis em: https://www.facebook.com/napufpr/.
} 
CALVO, Luciana Cabrini Simões. Comunidades de Prática: revisão dos estudos seminais e dos desenvolvidos na área de formação e atuação docentes. Signum: Estudos da Linguagem, v. 20, p. 186-217, 2017. Disponível em: https://www.uel.br/revistas/uel/ index.php/signum/article/view/27653/20864. Acesso em: 13 out. 2018. http://dx.doi. org/10.5433/2237-4876.2017v20n1p186.

CALVO, Luciana Cabrini Simões; FREITAS, Maria Adelaide de. (Orgs.) Comunidades de Prática: aspectos da formação de professores de línguas em foco. Coleção: Novas Perspectivas em Linguística Aplicada. Campinas, SP: Pontes, 2014.

FERREIRA, Sérgio. A Construção da Identidade do Ouvinte Aprendiz de Libras como Segunda Língua. Dissertação (Mestrado em Letras) - Setor de Ciências Humanas, Universidade Federal do Paraná. Curitiba, 2019. Disponível em: https://hdl.handle. net/1884/62948. Acesso em: 20 jan. 2020.

FOGACA, Francisco Carlos; HALU, Regina Celia. Comunidades de prática e construção identitária de formadores de professores em um programa de formação continuada. Revista Brasileira de Linguística Aplicada, Belo Horizonte, v. 17, n. 3, p. 427-454, 2017. Disponível em: https:/www.scielo.br/j/rbla/a/qbSGnQmnmQ4xk5qv6F9sL7B/ abstract/?lang=pt. Acesso em: 19 mar. 2018. https://doi.org/10.1590/1984-6398201711522.

FOUCAULT, Michel. AArqueologia do Saber. 6. ed. Rio de Janeiro, RJ: Martins Fontes, 2000.

GEE, James Paul. What is literacy? Journal of Education, v. 171, n. 1, p.18-25, 1989.

GRACIANO, Miriam Monteiro de Castro. A teoria biológica de Humberto Maturana e sua repercussão filosófica. 195 f. Dissertação (Mestrado em Lógica e Filosofia a ciência) - Faculdade de Filosofia e Ciências Humanas, UFMG. Belo Horizonte, 1997. Disponível em: http://hdl.handle.net/1843/BUBD-9RUG9L. Acesso em: 17 fev. 2016.

HALU, Regina Celia. Formação de formadoras de professoras de inglês em contexto de formação continuada (NAP-UFPR). $246 \mathrm{f}$. Tese (Doutorado em Letras) - Setor de Ciências Humanas, Letras e Artes, Universidade Federal do Paraná (UFPR), Curitiba, 2010. Disponível em: https://hdl.handle.net/1884/23793. Acesso em: 23 set. 2015.

JORDÃO, Clarissa Menezes. As lentes do discurso: letramento e criticidade no mundo digital. Trabalhos em Linguística Aplicada, v.46, n.1, p. 19-29, jan./jun. 2007a. Disponível em: https://www.scielo.br/j/tla/a/KR5KvJghbXM3HJf3RgJ8mhB/ abstract/?lang=pt, Acesso em: 29 mai. 2015. 
JORDÃO, Clarissa Menezes. English as a foreign language, globalization and conceptual questioning. Globalization, Society and Education, v.7, n. 1, p. 95-107, 2009. Disponível em: https://www.tandfonline.com/doi/abs/10.1080/14767720802677390. Acesso em: 14 abr. 2015. https://doi.org/10.1080/14767720802677390

JORDÃO, Clarissa Menezes. O que todos sabem... ou não: letramento crítico e questionamento conceitual. Revista CROP, v. 12, p. 21-46, $2007 \mathrm{~b}$.

JORDÃO, Clarissa Menezes; MARTINEZ, Juliana Zeggio; HALU, Regina Celia. Formação desformatada: práticas com professores de língua inglesa. Campinas: Pontes, 2011.

LAVE, Jean; WENGER, Étienne. Situated Learning: legitimate peripheral participation. Cambridge: Cambridge University Press, 1991.

MACHADO, Fernanda Ramos; GIL, Gloria. The processes of construction, deconstruction and reconstruction of an IFSC English language teacher's professional identity. D.E.L.T.A., v. 33, n.2, p. 383-411, 2017. Disponível em: https://revistas.pucsp. br/index.php/delta/article/view/34372/23625. Acesso em: 13 jul. 2018. http://dx.doi. org/10.1590/0102-445001030447361158

MATURAnA, Humberto. Cognição, Ciência e Vida Cotidiana. Belo Horizonte: Ed. UFMG, 2001.

MATURANA, Humberto. Emoções e Linguagem na Educação e na Política. Belo Horizonte: Ed. UFMG, 2005.

PARANÁ. Secretaria de Estado da Educação. Departamento de Educação Básica. Diretrizes Curriculares da Educação Básica: Língua Estrangeira Moderna. Curitiba: SEED, 2008. Disponível em: https://www.educacao.pr.gov.br/sites/default/arquivos_ restritos/files/documento/2019-12/dce_lem.pdf. Acesso em: 26 mar. 2017.

RAMOS, Samantha Gonçalves Mancini. O Programa de Desenvolvimento Educacional do Estado do Paraná e sua Proposta de Formação Continuada: foco nos grupos de trabalho em rede. 2011. 264 f. Tese (Doutorado em Estudos da Linguagem) - Universidade Estadual de Londrina, Londrina, 2011. Disponível em: http://www.bibliotecadigital.uel. br/document/?code=vtls000168376. Acesso em: 14 out. 2017.

SAUSSURE, Ferdinand de. Curso de Linguística Geral. São Paulo: Cultrix, 2006. 
SILVA, João Fabio Sanches. The Construction of English Teacher Identity in Brazil: a study in Mato Grosso do Sul. 261 f. Tese (doutorado) - Universidade Federal de Santa Catarina, Centro de Comunicação e Expressão, Programa de Pós-Graduação em Inglês (Estudos Linguísticos e Literários), Florianópolis, 2013. Disponível em: https:// repositorio.ufsc.br/xmlui/handle/123456789/122768. Acesso em: 20 jan. 2016.

TANACA, Jozélia Jane Corrente; MATEUS, Elaine Fernandes. Formação de professores/ as de Inglês para crianças: analisando espaços expandidos para aprendizagem em comunidade de prática. fólio Revista de Letras, v. 6, n. 2, p. 189-221, 2014. Disponível em: https://periodicos2.uesb.br/index.php/folio/article/view/3014.

WALESKO, Angela Maria Hoffmann. Formação Inicial e o Mito do Falante Nativo: construções identitárias de professores de inglês em uma comunidade de prática. $317 \mathrm{f}$. Tese (Doutorado em Letras) - Universidade Federal do Paraná, Curitiba, 2019.

WENGER, Étienne. Communities of practice: learning, meaning and identity. Cambridge, UK: Cambridge University Press, 1998.

WENGER, Étienne; MCDERMOTT, Richard; SNYDER, William. Cultivating Communities of Practice: a guide to managing knowledge. Boston, MA: Harvard Business School Press, 2002.

Recebido em: 23 abr. 2021.

Aceito em: 01 out. 2021. 